Article

\title{
Probability Risk of Heat- and Cold-Related Mortality to Temperature, Gender, and Age Using GAM Regression Analysis
}

\author{
Andri Pyrgou@ and Mattheos Santamouris * \\ Faculty of Built Environment, University of New South Wales, Sydney 2052, Australia \\ * Correspondence: m.santamouris@unsw.edu.au
}

Received: 7 February 2020; Accepted: 11 March 2020; Published: 11 March 2020

\begin{abstract}
We have examined the heat and cold-related mortality risk subject to cold and heat extremes by using a generalized additive model (GAM) regression technique to quantify the effect of the stimulus of mortality in the presence of covariate data for 2007-2014 in Nicosia, Cyprus. The use of the GAM technique with multiple linear regression allowed for the continuous covariates of temperature and diurnal temperature range (DTR) to be modeled as smooth functions and the lag period was considered to relate mortality to lagged values of temperature. Our findings indicate that the previous three days' temperatures were strongly predictive of mortality. The mortality risk decreased as the minimum temperature $\left(\mathrm{T}_{\min }\right)$ increased from the coldest days to a certain threshold temperature about $20-21^{\circ} \mathrm{C}$ (different for each age group and gender), above which the mortality risk increased as $\mathrm{T}_{\min }$ increased. The investigated fixed factors analysis showed an insignificant association of gender-mortality, whereas the age-mortality association showed that the population over 80 was more vulnerable to temperature variations. It was recommended that the minimum mortality temperature is calculated using the minimum daily temperatures because it has a stronger correlation to the probability for risk of mortality. It is still undetermined as to what degree a change in existing climatic conditions will increase the environmental stress to humans as the population is acclimatized to different climates with different threshold temperatures and minimum mortality temperatures.
\end{abstract}

Keywords: heatwave; diurnal temperature range; time-series; relative risk; health

\section{Introduction}

The relationship between hot and cold temperatures and mortality from respiratory and cardiovascular causes is well established. Governments and scientists are concerned with the increased frequency of temperature extremes as they are associated with increased morbidity and mortality $[1,2]$. Exploration of time series data in different countries has revealed a different temperature threshold of their population [3], necessitating different adaptation measures for the avoidance of the climate-change impact and to increase the countries' capacity to function at a forthcoming temperature [4-8]. It is of utmost importance for the threshold temperature to be determined per country or prevalent climate as there is a gap in the identification of the correct course of adaptation.

Mortality risk with respect to temperature has been assessed by scientists in northeastern Europe [9-12], the USA [13,14], and China [4] by considering fixed variables such as gender and age, resulting in contrasting findings of the threshold temperature and minimum mortality temperature (MMT). MMT is defined as the temperature at which there is the lowest risk of mortality according to a probability risk assessment. The question of whether fixed factors are affecting the MMT has to be addressed carefully in the eastern Mediterranean region because of the limited number of studies showing high MMT; $29-32{ }^{\circ} \mathrm{C}$ [15]. Generally, MMT has been found to be lower for populations 
living in colder climates and higher for populations living in warmer climates $[11,14,16]$ with the temperature-mortality relationship described as a J-, V-, or U-shaped curve.

People acclimatize to new temperatures at varying rates and to a certain extent based on physiological parameters such as age, gender, and other prevalent health conditions. The environmental stress even within a day may be a factor of increased cardiovascular and respiratory mortality. Moreover, the effect of exposure to extreme cold or heat conditions is not limited to the specific day, but may be delayed in time $[2,14,17]$. The diurnal temperature range (DTR) is defined as the difference between the daily minimum and maximum temperatures, with some studies correlating a high DTR with an increase of mortality risk [17].

To fill the above research gaps, we addressed the issue of temperature-related mortality via the use of the generalized additive model (GAM) regression technique. Using the GAM, we investigated the effect of same day temperatures and the weighted average temperature of the preceding three on mortality rates. The use of the GAM model to examine the short-term mortality relationship to regional minimum temperatures, maximum temperatures, and DTR variations revealed that MMT should be calculated using daily minimum temperature values.

\section{Methods}

\subsection{Study Area and Datasets}

Hourly weather data (temperature $\left[{ }^{\circ} \mathrm{C}\right]$ ) and daily mortality data for 2007 to 2014 inclusive were collected for two meteorological stations [18] in the urban $\left(35.17^{\circ} \mathrm{N}, 33.36^{\circ} \mathrm{E}\right)$ and $\operatorname{rural}\left(35.05^{\circ} \mathrm{N}, 33.54^{\circ} \mathrm{E}\right)$ areas of Nicosia, Cyprus. Nicosia is the capital of the island of Cyprus, located in the eastern basin of the Mediterranean Sea with a hot summer Mediterranean climate and hot semi-arid climate (in the northeastern part of island), according to the Köppen climate classification signs Csa (Mediterranean hot summer climates) and BSh (Hot semi-arid climates) [19], with warm to hot dry summers and wet winters.

The daily mortality counts were gathered only for circulatory and respiratory causes of death and included ischemic heart diseases (I20-I25), cerebrovascular diseases (I60-I69), other heart diseases (I30-I51), other circulatory diseases (I00-I15, I26-I28, I70-I99), influenza (J00-J99), pneumonia (J12-J18), chronic lower respiratory diseases (J40-J47), and other respiratory causes (J00-J06, J20-J39, J60-J99), according to the ICD-10-CM (International Classification of Diseases, Tenth Revision, Clinical Modification). The daily mortality data were provided by the Health Monitoring Unit of the Ministry of Health of Cyprus.

\subsection{Log-Linear Regression of Mortality-Temperature Relation}

The log mortality based on temperature was assumed to be smooth, but not necessarily linear and a generalized additive model (GAM) was used. This GAM offered a high quality of prediction of the dependent variable (log mortality rate) from the various distributions by estimating unspecific (non-parametric) functions of the predictor variables $x j$, which were connected to the dependent variable (mortality rate) via a link function.

As the death on a given day is not only a function of the same-day exposure to temperature but is also affected by exposure during a certain lag period, we also used the weighted average temperature of the preceding three days prior to the death. The lag period was determined using the cross correlation function (CCF) in RStudio software. Cross-correlation analysis showed the similarity of two series as a function of the displacement of one relative to the other. Figure 1 shows the cross correlation of mortality rate with minimum daily temperature for a cold period (months NDJFMA) and a hot period (months MJJASO). Similar analysis was also done for the mean and the maximum daily temperatures. The mortality rate decreased with increasing temperature during the cold period (Figure 1a) with a lag period of four days (that is, the highest peak of mortality four days after the coldest temperature), whereas the mortality rate reached a peak on the same day (no lag period) as 
the maximum temperature (Figure 1b). The lag period of cross correlation function (CCF analysis) that had an effect on mortality rate was four days during the cold period and 0 days during the hot period. In an individual, the lag period should not be regarded as a well-defined interval as it may vary according to the magnitude of the temperature and individual characteristics such as acclimatization habits to heat, genetic background, and income.
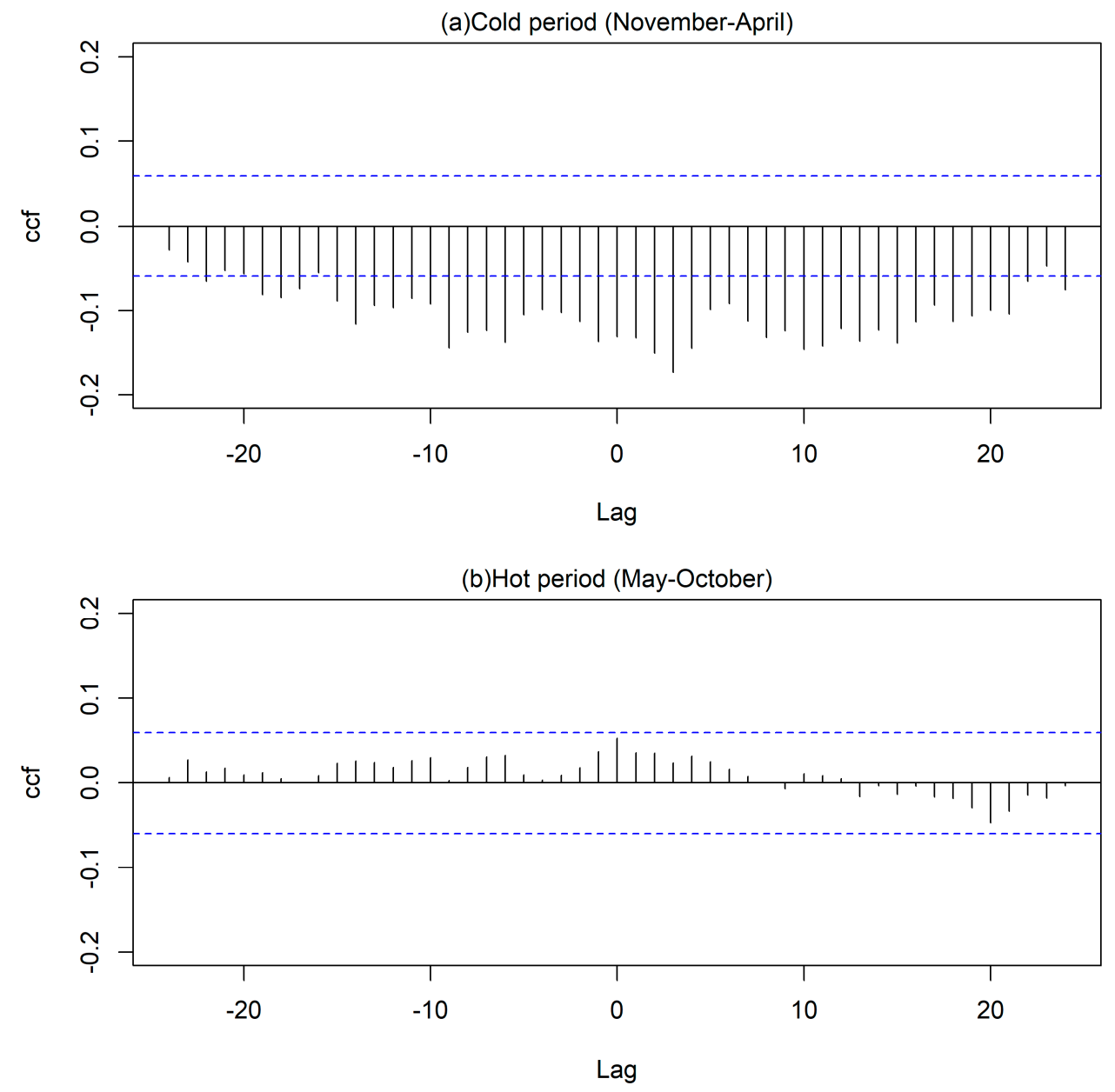

Figure 1. Cross correlation for (a) minimum daily temperature ( $x$ ) and mortality (y) for months November to April; (b) Minimum daily temperature (x) and mortality (y) for months May to October). Dotted blue horizontal lines show the $95 \%$ significance limits.

To address the lagged dependence of mortality on temperature, the same-day maximum $\left(\mathrm{T}_{\max }\right)$ and minimum $\left(\mathrm{T}_{\min }\right)$ temperatures, the same-day diurnal temperature range (DTR), and the average temperature of the preceding three days $\left(\mathrm{T}_{\max }[-3]\right.$ and $\mathrm{T}_{\min }[-3]$, respectively) and weighted average DTR of the preceding three days (DTR[-3]) were used in order to closer examine the lag period of four days found during the cold period. Diurnal temperature range is the temperature difference of the daily maximum value and the daily minimum value [20].

The advantage of GAM was to limit the error in the prediction of the dependent variable - mortality rate-by defining the model in terms of smooth function. In the GAM, the degree of smoothness of the estimated mortality-temperature relative risk curve is controlled by its number of degrees of freedom (df). Many degrees of freedom were preferred to allow highly nonlinear shapes.

$$
\text { Relative risk of Mortality }=\beta+\mathrm{f}_{1}\left(\mathrm{x}_{1}\right)+\mathrm{f}_{2}\left(\mathrm{x}_{2}\right)+\ldots+\mathrm{f}_{\mathrm{m}}\left(\mathrm{x}_{\mathrm{m}}\right)
$$


The functions fj may have a parametric or non-parametric form. xj represents the temperature term, which could be $\mathrm{T}_{\min }, \mathrm{T}_{\max }, \mathrm{T}_{\max }[-3], \mathrm{T}_{\min }[-3]$, DTR or DTR[-3], as explained above. The relative risk of mortality was calculated using the gam function of the mgcv package in RStudio software [21]. The limitation of this short-term temperature analysis was that longer-term population characteristics were not considered such as health behaviors (smoking, drinking), comorbidities (hypertension, diabetes, cancer, etc.), medications, and access to health care.

\section{Results}

\section{Temperature-Mortality Relative Risk Analysis}

Figure 2 shows the temperature-mortality relative risk function estimated for Nicosia using GAM analysis. We examined six temperature parameters: the maximum daily temperature $\left(\mathrm{T}_{\max }\right)$, the weighted average of the maximum daily temperatures of the preceding three days $\left(\mathrm{T}_{\max }[-3]\right)$, the minimum daily temperature $\left(\mathrm{T}_{\min }\right)$, the weighted average of the minimum daily temperatures of the preceding three days $\left(\mathrm{T}_{\min }[-3]\right)$, the diurnal temperature range (DTR) of the day, and the weighted average of the DTR of the preceding three days (DTR[-3]). A smooth function of time with $50 \mathrm{df}$ over the investigated years was used for the model. Similar findings were also found for smaller and larger df.
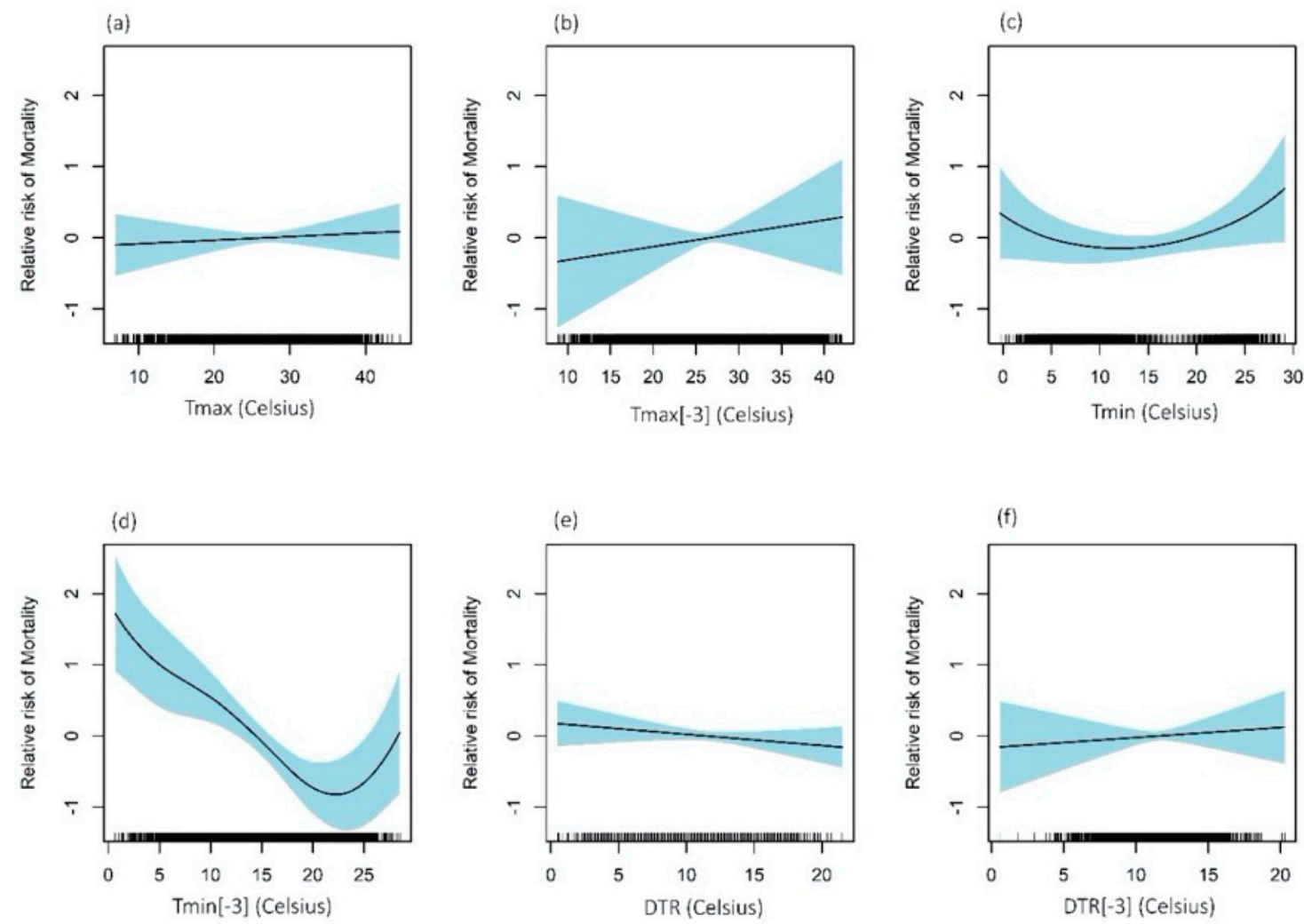

Figure 2. Temperature-mortality relative risk functions for Nicosia, Cyprus, 2004-2014. $\mathrm{T}_{\max }, \mathrm{T}_{\max }[-3]$, $\mathrm{T}_{\min }, \mathrm{T}_{\min }[-3]$, DTR, and DTR[-3] are shown in (a-f), respectively.

The relationship between maximum daily temperature and probability risk of mortality seems linear, with a steeper slope when the average of the preceding three days' maximum temperature is considered. The analysis of the minimum daily temperature with respect to the mortality's probability risk (Figure 2c,d) showed a $U$ shape for same-day relationship and an inverse $J$ shape when $T_{\min }[-3]$ was used. That is, mortality risk decreased as the minimum temperature increased from the coldest temperatures and began to rise as the temperature increased from a certain threshold temperature 
(approximately $22^{\circ} \mathrm{C}$ ). The applied model offers flexibility and agrees with Curriero et al. [14] as the population in a warm region (such as Nicosia) tends to be more vulnerable to cold rather than those residing in cold climates who are most sensitive to heat.

The analysis of DTR (Figure 2d,f) showed no significant results (mortality relative risk close to zero), insinuating that the human body could adapt to any DTR within the same day. These results thus need to be interpreted with attention, as previous studies have reported noteworthy findings of DTR with the probability risk of mortality, therefore a more focused analysis sub-grouped by age could elaborate on better assumptions.

Further analysis focused on the $\mathrm{T}_{\min }$ of the current day and the weighted average of the preceding three days $\left(\mathrm{T}_{\min }[-3]\right)$ by subgrouping the risk by gender and age groups. The variables gender and age were related using GAM with these minimum temperatures and the results are shown in Figure 3a,b. According to Figure 3a,b, cold temperatures impose a greater risk than hot temperatures, but other factors such as respiratory epidemics, usually present in winter, made unclear the exact role of temperatures on increased mortality.

(a)

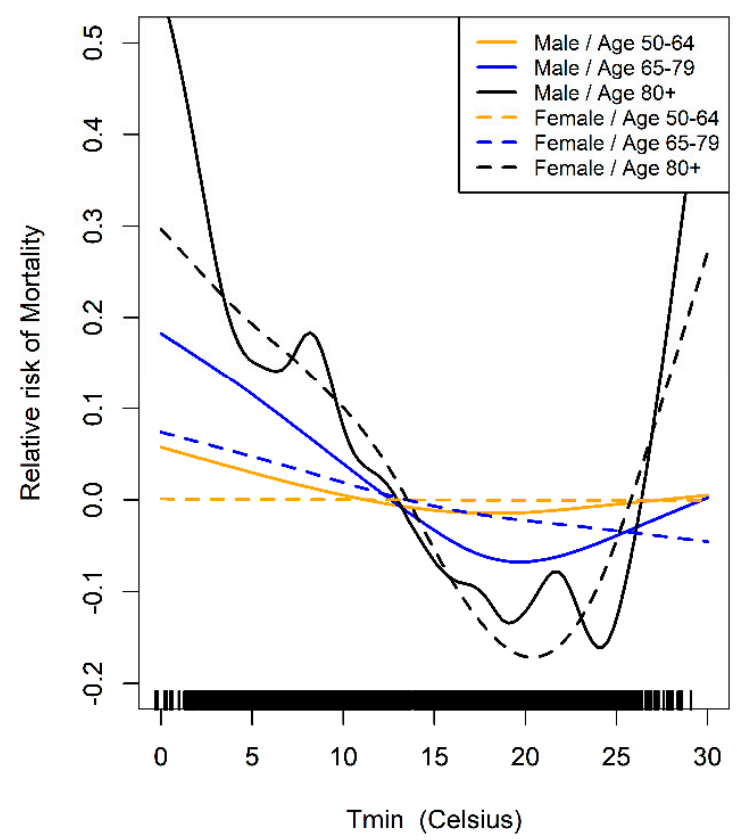

(b)

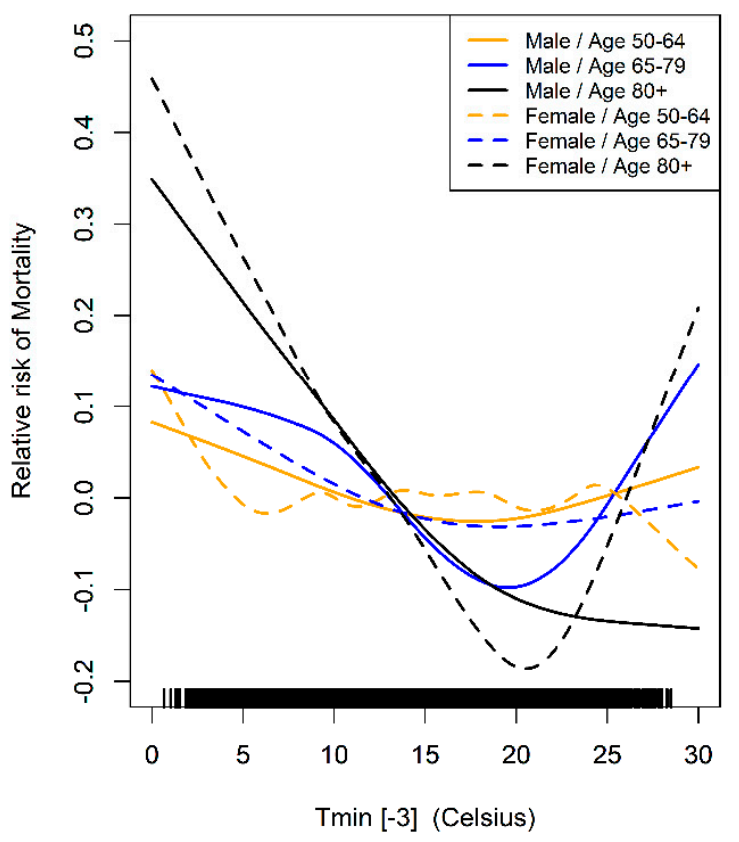

Figure 3. Mortality relative risk functions for Nicosia, Cyprus, 2007-2014 with (a) minimum temperature of the same day $\left(\mathrm{T}_{\min }\right)$, (b) Weighted average minimum temperature of the preceding three days $\left(\mathrm{T}_{\min }[-3]\right)$.

On the other hand, high minimum temperatures and heatwaves were also associated with increased mortality. Heat waves have gained more attention due to the urban warming attributed to greenhouse gases and other anthropogenic sources. Other studies have shown that different cities have different sensitivities to extremes in temperature and that the latitude and local climate are factors to consider [14,22]. Air conditioning and human behavior can substantially modify the adverse effects of high temperatures, but even in the hot city of Nicosia, where people are more accustomed to higher temperatures and use air conditioning frequently, the effect of heat on health showed increasing deaths during heat waves. Thus, adaptation should be readdressed and governments should aim for adequate people awareness.

Figure 4 shows the relative risk of mortality for the DTR of the same day and the weighted average DTR of the preceding three days. Kan et al. (2007) hypothesized that large diurnal temperature change might be a source of additional environmental stress, leading to a greater risk factor for death [17]. 
In contrast, our results showed a greater risk at DTR in the range of $6-8{ }^{\circ} \mathrm{C}$, and smaller risk at larger DTRs. Men and women aged 50-64 (magenta lines) were not affected by the variations in DTR throughout the day or the preceding three days. Men 65 years and over had a greater relative risk for DTR smaller than $5{ }^{\circ} \mathrm{C}$, whereas for larger DTR, there was a negative relative risk, showing that large DTR did not impose a risk factor for death in Nicosia. Overall, we found that DTR was independently associated with daily mortality in Nicosia and that fluctuations in DTR appeared to mostly affect people over 80 , probably because they have reduced ability to regulate body temperatures, thus making them marginally more vulnerable.

(a)

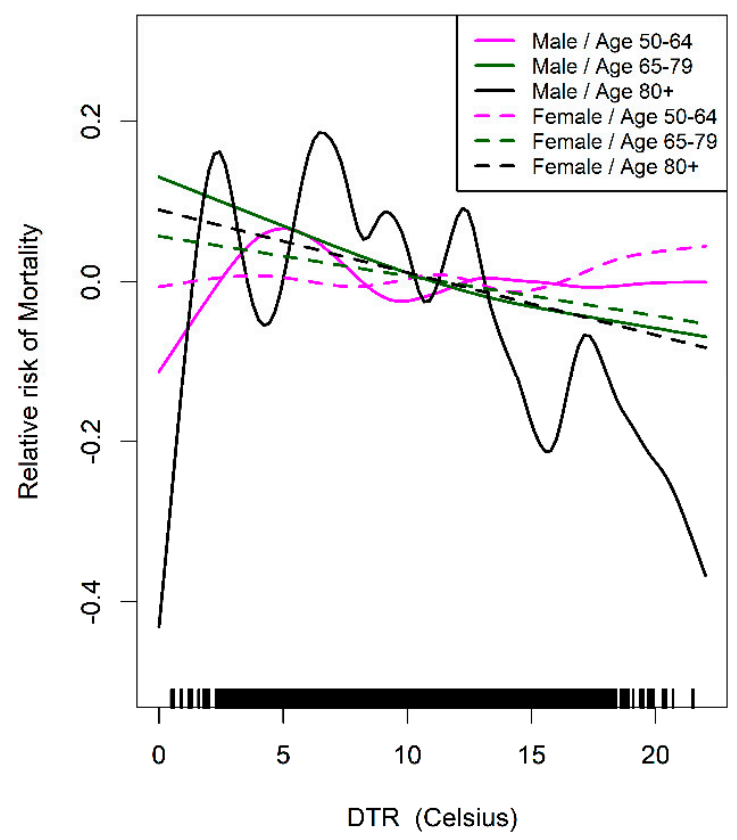

(b)

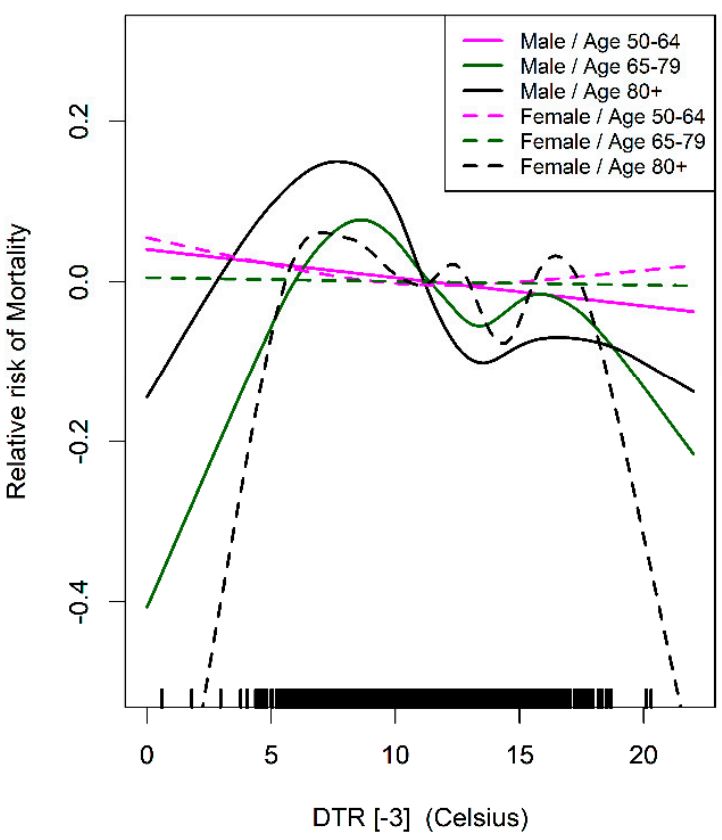

Figure 4. Mortality relative risk functions for Nicosia, Cyprus, 2007-2014 with (a) DTR of the same day, (b) Weighted average DTR of the preceding three days (DTR[-3]).

\section{Discussion}

The mortality risk by respiratory and circulatory causes for different age groups and per gender in relation to temperature has been examined. We employed two regression techniques to evaluate the impact of fixed and time-dependent factors on the vulnerability to temperature-mortality associations for 6882 deaths resulting from cardiovascular and respiratory causes between the years 2007 and 2014, in Nicosia, Cyprus. To model the relationship between temperature and mortality, we used the generalized additive model (GAM) to assess the interaction between a variable and the observation time and to interpret quantitative results. The GAM model revealed significantly increased mortality on hot (no lag period) and cold days (with a lag of 3-4 days), agreeing with a similar study in Estonia [4,9]. The adverse effects of heat on health are usually more direct with increased mortality on the same day or a couple of days after a heatwave [2,10]. As proposed by Curriero et al. [14], adaptation of populations to their local climate is evident by the increased health risk in relation to cold temperatures in warmer climates and on the contrary in relation to high temperature in colder climates. In warmer climates such as Nicosia, the people are more acclimatized to high temperature conditions and therefore, a steeper increase of the relative risk of mortality in colder conditions was observed.

The most important result to emerge from the analysis is that in the investigated area, the threshold temperature was about $21^{\circ} \mathrm{C}$, supporting the assumption that people in the area are more acclimatized to higher temperatures. MMT has been calculated in over 400 locations using the mean daily temperatures 
showing values of $29-32{ }^{\circ} \mathrm{C}$ in the eastern Mediterranean region and over $23{ }^{\circ} \mathrm{C}$ in the rest of the Mediterranean [15]. The probability risk of mortality using GAM revealed a stronger relation with the minimum daily temperature, so future studies should focus on the investigation of MMT using daily minimum temperatures. A similar GAM analysis in Shanghai [17] found smaller relative risk for elderly people with values of 0.3 , therefore in Nicosia, where the population is more accustomed to higher temperatures, they are more vulnerable to lower temperatures with relative risk up to 0.5 .

Our cross-correlation results agreed with previous studies where the effects of heat on mortality rate shortly after temperatures start to increase, whereas the effects of cold may take longer to emerge, and, depending on the latitude and the local climate, these periods may vary $[2,9,23]$. The results are in complete agreement with previous studies [24], finding no difference in heat-mortality risk between men and women, and weak evidence of a higher association of cold-mortality risk for men. The results are also in line with a study in Nicosia and a study in Stockholm [11], which found a difference in heat wave duration effects by age groups [2], while the increasing susceptibility to cold temperatures in the elderly has not been shown before.

This study has not confirmed previous research on DTR. In fact, in contrast with what was previously thought, we found that DTR does not have a noteworthy effect on mortality risk. This serves to allow for more focused research on environmental stress factors and whether prolonged duration of extreme heat or cold conditions is more important than within day variations of temperature.

A limitation of this study is the poor correlation of indoor and outdoor temperatures due to a number of modifying factors such as air conditioning, ventilation, and clothing. Time indoors affects the individual's exposure as well as workplace conditions and other comorbidities. Another limitation is that we did not adjust the analysis for micro-level socio-economic or demographic variables or other comorbidities that could have a potential confounding or modifying effect on the mortality-temperature relationship.

\section{Conclusions}

The main concern of the paper was to examine the mortality risk in relation to high or low temperatures of different age groups and compare them between the two genders. Mortality risk has only been evaluated for respiratory and circulatory causes. Particular attention is paid to elderly people, over 65 years old, as the results have shown a great vulnerability to ambient air temperature. We have addressed not only minimum and maximum daily temperatures, but also the diurnal temperature range (DTR) in order to examine the sensitivity for within the same day air temperature variations.

The originality of our approach lies in the fact that we have combined the cross correlation analysis to identify the effect of the preceding days' temperature with the generalized additive model (GAM) regression technique. From the research that has been performed, it is possible to conclude that there was increased mortality on extremely hot and cold days. The effects of the heat had no lag period, whereas cold effects had a lag effect of 3-4 days. The existence of these responses implies that in warmer climates, people are more acclimatized to high temperatures, and therefore a higher mortality risk was observed at colder temperatures with a lag of three days.

The approach used in this paper is applicable to several environmental areas such as air quality analysis where the results may be subjective to a delay period and may slowly diminish human health and well-being. The results of this study should alert organizations and governments on the possible impacts of climate change on public health by not considering adaptation. The identification of a threshold temperature per latitude and local climate will assist in the evaluation of the adaptation capacity of a specific population. This threshold temperature, according to our results, should be calculated using the daily minimum temperature. Nevertheless, even if humans become fully acclimatized to high temperatures, their health may still be negatively affected as a result of the poorer air quality associated with extremely high temperatures $[2,25]$. 
On the basis of the promising findings presented in this paper, work on the remaining issues is continuing to examine whether socio-economic or demographic variables or other comorbidities could have a potential confounding or modifying effect on the mortality-temperature relationship.

Author Contributions: M.S. conceived the research topic. A.P. obtained the datasets, created the figures, and analyzed the results. Both authors (A.P. and M.S.) contributed in the discussion of the results and reviewed the manuscript. All authors have read and agreed to the published version of the manuscript.

Acknowledgments: The authors are grateful to the Ministry of Agriculture, Rural Development, and Environment (MADRE) of the Republic of Cyprus for the Department of Meteorology historical meteorological data, and the Health Monitoring Unit of the Ministry of Health of Cyprus for the mortality data. The ideas and opinions expressed herein are those of the authors. Endorsement of these ideas and opinions by the Ministry of Health of Cyprus is not intended nor should it be inferred.

Conflicts of Interest: The authors declare no conflicts of interest.

\section{References}

1. Hondula, D.M.; Balling, R.C.; Vanos, J.K.; Georgescu, M. Rising Temperatures, Human Health, and the Role of Adaptation. Curr. Clim. Chang. Rep. 2015, 1, 144-154. [CrossRef]

2. Pyrgou, A.; Santamouris, M. Increasing Probability of Heat-Related Mortality in a Mediterranean City Due to Urban Warming. Int. J. Environ. Res. Public Health 2018, 15, 1571. [CrossRef] [PubMed]

3. Coffel, E.D.; Horton, R.M.; De Sherbinin, A. Temperature and humidity based projections of a rapid rise in global heat stress exposure during the 21st century. Environ. Res. Lett. 2018, 13. [CrossRef]

4. Chen, R.; Yin, P.; Wang, L.; Liu, C.; Niu, Y.; Wang, W.; Jiang, Y.; Liu, Y.; Liu, J.; Qi, J.; et al. Association between ambient temperature and mortality risk and burden: Time series study in 272 main Chinese cities. BMJ 2018, 363. [CrossRef] [PubMed]

5. Rocklöv, J.; Forsberg, B.; Ebi, K.; Bellander, T. Susceptibility to mortality related to temperature and heat and cold wave duration in the population of Stockholm County, Sweden. Glob. Health Action 2014, 7, 1-11. [CrossRef] [PubMed]

6. Gronlund, C.J.; Berrocal, V.J.; White-Newsome, J.L.; Conlon, K.C.; O'Neill, M.S. Vulnerability to extreme heat by socio-demographic characteristics and area green space among the elderly in Michigan, 1990-2007. Environ. Res. 2015. [CrossRef]

7. Goggins, W.B.; Ren, C.; Ng, E.; Yang, C.; Chan, E.Y.Y. Effect modification of the association between meteorological variables and mortality by urban climatic conditions in the tropical city of Kaohsiung. Taiwan. Geospatial Health 2013. [CrossRef]

8. Milojevic, A.; Armstrong, B.G.; Gasparrini, A.; Bohnenstengel, S.I.; Barratt, B.; Wilkinson, P. Methods to estimate acclimatization to urban heat island effects on heat-and cold-related mortality. Environ. Health Perspect. 2016, 124, 1016-1022. [CrossRef]

9. Orru, H.; Åström, D.O. Increases in external cause mortality due to high and low temperatures: Evidence from northeastern Europe. Int. J. Biometeorol. 2017, 61, 963-966. [CrossRef]

10. Åström, D.O.; Åström, C.; Rekker, K.; Indermitte, E.; Orru, H. High summer temperatures and mortality in Estonia. PLoS ONE 2016, 11, 1-10. [CrossRef]

11. Oudin Åström, D.; Tornevi, A.; Ebi, K.L.; Rocklöv, J.; Forsberg, B. Evolution of minimum mortality temperature in Stockholm, Sweden, 1901-2009. Environ. Health Perspect. 2016, 124, 740-744. [CrossRef] [PubMed]

12. Huynen, M.M.T.E.; Martens, P.; Schram, D.; Weijenberg, M.P.; Kunst, A.E. The impact of heat waves and cold spells on mortality rates in the Dutch population. Environ. Health Perspect. 2001, 109, 463-470. [CrossRef]

13. Anderson, B.G.; Bell, M.L. Weather-related mortality: How heat, cold, and heat waves affect mortality in the United States. Epidemiology 2009, 20, 205. Available online: http://www.pubmedcentral.nih.gov/articlerender. fcgi?artid=3366558\&tool=pmcentrez\&rendertype=abstract (accessed on 15th December 2019). [CrossRef]

14. Curriero, F.C.; Heiner, K.S.; Samet, J.M.; Zeger, S.L.; Strug, L.; Patz, J.A. Temperature and mortality in 11 cities of the eastern United States. Am. J. Epidemiol. 2002. [CrossRef] [PubMed]

15. Yin, Q.; Wang, J.; Ren, Z.; Li, J.; Guo, Y. Mapping the increased minimum mortality temperatures in the context of global climate change. Nat. Commun. 2019, 10, 4640. [CrossRef] [PubMed] 
16. Baccini, M.; Biggeri, A.; Accetta, G.; Kosatsky, T.; Katsouyanni, K.; Analitis, A.; Anderson, H.R.; Bisanti, L.; D'Ippoliti, D.; Danova, J.; et al. Heat effects on mortality in 15 European cities. Epidemiology 2008. [CrossRef] [PubMed]

17. Kan, H.; London, S.J.; Chen, H.; Song, G.; Chen, G.; Jiang, L.; Zhao, N.; Zhang, Y.; Chen, B. Diurnal temperature range and daily mortality in Shanghai, China. Environ. Res. 2007, 103, 424-431. [CrossRef]

18. Republic of Cyprus. Department of Meteorology, Cyprus. Available online: http://www.moa.gov.cy/moa/ ms/ms.nsf/DMLannual_en/DMLannual_en?OpenDocument (accessed on 25th April 2019).

19. Peel, M.C.; Finlayson, B.L.; McMahon, T.A. Updated world map of the Koppen-Geiger climate classification. Hydrol. Earth Syst. Sci. 2007, 11, 1633-1644. [CrossRef]

20. Pyrgou, A.; Santamouris, M.; Livada, I. Spatiotemporal Analysis of Diurnal Temperature Range: Effect of Urbanization, Cloud Cover, Solar Radiation, and Precipitation. Climate 2019, 7, 89. [CrossRef]

21. Wood, S. Mgcv: Mixed GAM Computation Vehicle with Automatic Smoothness Estimation. Available online: https://cran.r-project.org/web/packages/mgcv/index.html (accessed on 20 October 2019). [CrossRef]

22. Braga, A.L.F.; Zanobetti, A.; Schwartz, J. The effect of weather on respiratory and cardiovascular deaths in 12 U.S. cities. Environ. Health Perspect. 2002, 110, 859-863. [CrossRef]

23. Brooke Anderson, G.; Bell, M.L. Heat waves in the United States: Mortality risk during heat waves and effect modification by heat wave characteristics in 43 U.S. communities. Environ. Health Perspect. 2011, 119, 210-218. [CrossRef] [PubMed]

24. Son, J.-Y.; Liu, J.C.; Bell, M.L. Temperature-related mortality: a systematic review and investigation of effect modifiers. Environ. Res. Lett. 2019, 14, 073004. [CrossRef]

25. Pyrgou, A.; Hadjinicolaou, P.; Santamouris, M. Enhanced near-surface ozone under heatwave conditions in a Mediterranean island. Sci. Rep. 2018, 8, 9191. [CrossRef] [PubMed]

(C) 2020 by the authors. Licensee MDPI, Basel, Switzerland. This article is an open access article distributed under the terms and conditions of the Creative Commons Attribution (CC BY) license (http://creativecommons.org/licenses/by/4.0/). 